\title{
The Path to Improve Kesterite Solar Cell Efficiency
}

\author{
Maykel Courel, ${ }^{*, a}$ A. Arce-Plaza, ${ }^{b}$ D. O. Oseguera-Galindo, ${ }^{a}$ and O. Vigil-Galán ${ }^{c}$ \\ ${ }^{a}$ Departamento de Ciencias Naturales y Exactas, Centro Universitario de los Valles (CUValles), \\ Universidad de Guadalajara, Carretera Guadalajara-Ameca Km. 45.5, C.P. 46600, Ameca, Jalisco, Mexico \\ ${ }^{b}$ Escuela Superior de Ingeniería y Arquitectura, Unidad Zacatenco del Instituto Politécnico Nacional (ESIAZ-IPN) \\ CP 07738 CDMX, Mexico \\ ${ }^{c}$ Escuela Superior de Física y Matemáticas_Instituto Politécnico Nacional (ESFM-IPN), 07738, CDMX, Mexico \\ Email: maykelcourel@gmail.com (M. C.)
}

\begin{abstract}
Kesterite semiconductors such as $\mathrm{Cu}_{2} \mathrm{ZnSnS}{ }_{4}, \mathrm{Cu}_{2} \mathrm{ZnSnSe}{ }_{4}$ and $\mathrm{Cu}_{2} \mathrm{ZnSn}(\mathrm{SSe})_{4}$ have received a great deal of attention from scientific community for solar cell applications since they present $p$-type conductivity, direct band-gap transitions, a relatively high absorption coefficient and a band-gap that can be tailored in the range of $1.0-1.5 \mathrm{eV}$ as a function of Se/S compositional ratio. Besides, these materials are based on abundant and low toxicity elements. In spite of the great effort carried out by the scientific community to promote device performance, Kesterite solar cell efficiency is still limited to values lower than $13 \%$. In this sense, new strategies are required to overcome currently reported values. In this paper, a minireview on the state of the art concerning Kesterite solar cell technology is presented. Different current trends to promote Kesterite solar cell efficiency are presented and discussed.
\end{abstract}

Keywords Kesterite solar cells, thin film solar cells, electrical and optical properties, limiting factors, defects

\section{Introduction}

The current thin film solar cell technology is mainly based on absorber compounds such as CdTe and CIGS, which have allowed efficiency values higher than $20 \% .{ }^{[1]}$ However, the scarcity of In and $\mathrm{Te}$ as well as the toxicity of $\mathrm{Cd}$ constitute important drawbacks for scaling this technology up. In this sense, the search for non-toxic materials based on abundant elements has led the scientific community to Kesterite compounds such as $\mathrm{Cu}_{2} \mathrm{ZnSnS}_{4}, \mathrm{Cu}_{2} \mathrm{ZnSnSe}$ and $\mathrm{Cu}_{2} \mathrm{ZnSn}-$ $(\mathrm{S}, \mathrm{Se})_{4}$. These semiconductors are described by direct bandgap transitions, high absorption coefficient values higher than $10^{4} \mathrm{~cm}^{-1}$, p-type conductivity and a tailored band-gap in the range of $1.0-1.5 \mathrm{eV}$ as reported elsewhere. ${ }^{[2]}$ All of these properties are main starting points when it comes to apply a material as an absorber to a solar cell. At its beginnings, Kesterite family received a great deal of attention from scientific community reaching a solar cell efficiency promotion from $0.66 \%$ to $12.6 \%$ in about 16 years. ${ }^{[3,4]}$ Nevertheless, this new record efficiency is quite lower than values reported for CdTe and CIGS technology and seems to be unbreakable. In comparison to other emerging technologies such as Perovskites, Kesterites have received less attention with fewer publications to date related to photovoltaic applications. ${ }^{[5]}$ This is a direct result of some problems concerning Kesterite bulk material and Kesterite/buffer interface as will be discussed in this minireview.

Several deposition techniques including but not limited to magnetron sputtering, ${ }^{[6,7]}$ thermal evaporation, ${ }^{[8]}$ sol gel, ${ }^{[9]}$ screen printed, ${ }^{[10]}$ electrodeposition, ${ }^{[11]}$ photochemical deposition, ${ }^{[12]}$ co-evaporation, ${ }^{[13]}$ hydrazine based deposition, ${ }^{[14]}$ and spray pyrolysis ${ }^{[15-17]}$ have been used for Kesterite thin film deposition. In regardless of the deposition technique, there are several factors such as secondary phase formation, Kesterite bulk defects, absorber/buffer defects that are limiting device performance. ${ }^{[2]}$ In order to overcome these problems, some strategies that go from classical thermal annealing processes to Kesterite doping with other elements have been proposed. However, none of these approaches has been able to provide efficiency values higher than the record one.

This work presents a minireview on the main limiting factors concerning Kesterite solar cells. Besides, the current trends to promote Kesterite solar cell efficiency are summarized. Particular interest will be given to proposals focused on reducing bulk and interface absorber/buffer defects, secondary phases and a better absorber/Kesterite band-alignment.

\section{Main limiting factors concerning Kesterite solar cells}

Before getting into the current trends presented to improve Kesterite solar cell efficiency, it is necessary to understand the main limiting factors associated to this technology. $\mathrm{Cu}_{2} \mathrm{ZnSnS}_{4}$, $\mathrm{Cu}_{2} \mathrm{ZnSnSe}_{4}$ and $\mathrm{Cu}_{2} \mathrm{ZnSn}(\mathrm{S}, \mathrm{Se})_{4}$ solar cells consist of a $\mathrm{p}-\mathrm{n}$ junction, where the absorber plays an important role as well as the buffer layer in the optoelectronic properties. Figure 1 illustrates the most common used configuration for Kesterite solar cells, where CdS (n-type material) constitutes the buffer layer. Either $\mathrm{ZnO}: \mathrm{Al}(\mathrm{AZO})$ or $\mathrm{SnO}_{2}$ : In (ITO) has been widely used as front contact showing good characteristics in solar cells. ${ }^{[2]}$ Conversely, some problems associated to the absorber and its coupling with the CdS have been identified as the main limiting factors. ${ }^{[2]}$

\section{Kesterite bulk properties}

An important feature of $\mathrm{Cu}_{2} \mathrm{ZnSn}(\mathrm{S}, \mathrm{Se})_{4}$ semiconductor is its band-gap tailoring with Se/S compositional ratio. Figure 2 


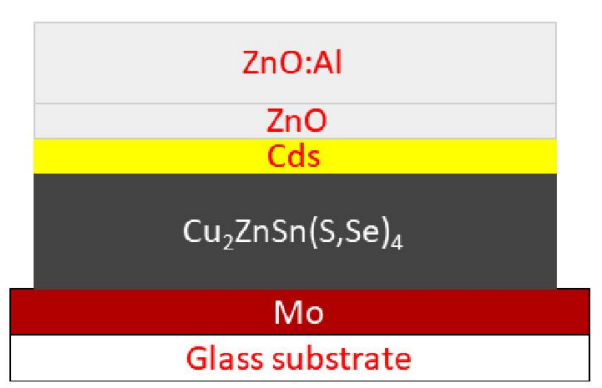

Figure 1 Sketch of Kesterite solar cells.

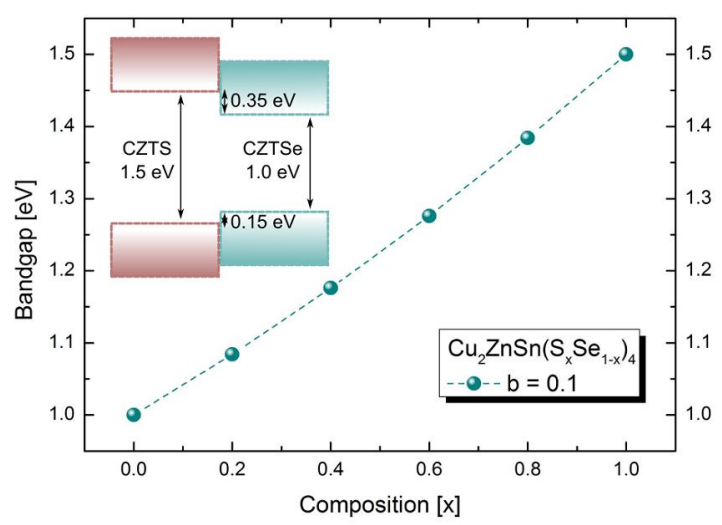

Figure 2 Band-gap variation for $\mathrm{Cu}_{2} \mathrm{ZnSn}(\mathrm{S}, \mathrm{Se})_{4}$ semiconductor. ${ }^{[18]}$

shows an almost linear band-gap variation from 1.5 to $1.0 \mathrm{eV}$ with Se composition incorporation. ${ }^{[18]}$ In this sense, an optimized band-gap can be obtained, which could provide efficiency values about $28 \%$ according to Shockley-Queisser limit. ${ }^{[19]}$ However, under such optimized conditions for band-gap, an efficiency of $12.6 \%$ has been reported as presented in Figure $3,{ }^{[4]}$ which is quite lower than the expected one. Among the different device parameters shown in Figure 3 , it is clearly observed that a low open-circuit voltage $\left(V_{o c}\right)$ is limiting this technology. In fact, low $V_{\text {oc }}$ values have been identified as the main issue of Kesterite solar cells. ${ }^{[2]}$ Different factors such as defects at Kesterite bulk and/or Kesterite/buffer interface as well as Kesterite/buffer band alignment are known to reduce $V_{\text {oc }}$ values due to carrier losses through recombination. ${ }^{[20-23]}$ Therefore, special attention should be given to all of these important points.

\section{Formation of secondary phases}

Since Kesterite material consists of four or more elements, it is very likely the formation of secondary phases depending on elemental composition. Secondary phases such as $\mathrm{ZnS}(\mathrm{Se})$, $\mathrm{SnS}(\mathrm{Se})_{2}, \mathrm{Cu}_{2} \mathrm{~S}(\mathrm{Se}), \mathrm{Cu}_{2} \mathrm{SnS}(\mathrm{Se})_{3}$ have been widely reported when depositing Kesterite compound, which could have a negative impact on solar cells. ${ }^{[2]}$ This result is a direct consequence of the very narrow region, where Kesterite phase is formed as presented in Figure 4. ${ }^{[25,26]}$ Therefore, the processing of pure-Kesterite material is sometimes quite challenging. In order to identify Kesterite phase, several techniques such as XRD and Raman are used. It is important to point out that XRD is not a conclusive technique on phase formation as some secondary phases present their contribution at same $2 \theta$ value of Kesterite ${ }^{[17]}$ being Raman measurement more accurate. For pure phase determination, different laser sources during Raman measurements should be used. In particular, laser sources of 514 and $325 \mathrm{~nm}$ are mandatory to conclude not only on

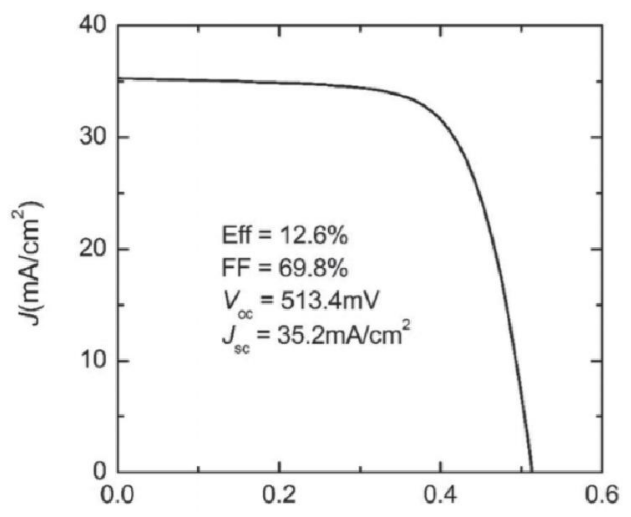

Figure $3 \mathrm{~J}-\mathrm{V}$ characteristic for record $\mathrm{Cu}_{2} \mathrm{ZnSn}(\mathrm{S}, \mathrm{Se})_{4}$ solar cell. ${ }^{[4]}$

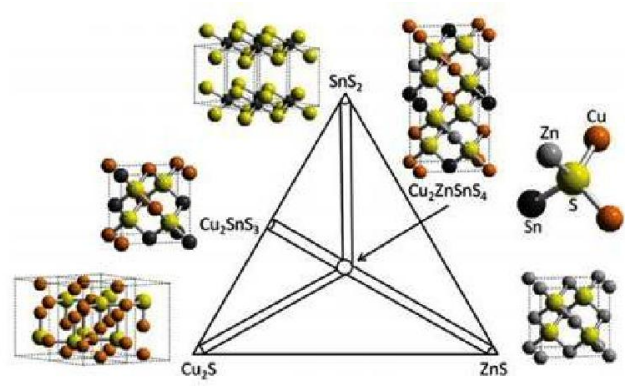

Figure $4 \quad \mathrm{Cu}_{2} \mathrm{ZnSnS}_{4}$ and secondary phases formation as function of composition. ${ }^{[25,26]}$

Kesterite compound formation but also on the absence or presence of $\mathrm{ZnS}$ phase due to resonant condition. ${ }^{[24]}$

One important required condition for good performing Kesterite solar cell is $\mathrm{Cu}$-poor and $\mathrm{Zn}$-rich samples. It has been widely reported that $\mathrm{Cu} /(\mathrm{Zn}+\mathrm{Sn})$ and $\mathrm{Zn} / \mathrm{Sn}$ compositional ratios about 0.85 and 1.2 , respectively, provide the best solar cell efficiency, while stoichiometric compositional ratios provide the poorest performance as observed in Figure $5 .{ }^{[27]}$ This behavior is a direct consequence of the tendency to form $\mathrm{Cu}_{\mathrm{zn}}$ antisite defects under stoichiometric condition, degrading solar cell performance. ${ }^{[28]}$ In this sense, Cu-poor and Zn-rich conditions would reduce the formation of such defects. On the other hand, under optimal compositional ratios, the formation of secondary phases is reduced while a major presence of these phases is observed under stoichiometric condition as previously reported. ${ }^{[24]}$ Therefore, Cu-poor and Zn-rich samples are mandatory to fabricate Kesterite solar cells. In order to remove secondary phases, different chemical etchings have been previously performed as presented in Reference [29].

\section{Bulk defects formation}

Different bulk defects such as substitutional, interstitial and vacancies are likely to be formed in Kesterite compounds as a result of the presence of at least four elements. The energy of some defects within the band-gap is presented in Figure 6, where the formation of more than ten types of defects is illustrated. ${ }^{[28,30]}$ In particular, p-type conductivity of Kesterite compound is mainly a result of the formation of $\mathrm{Cu}_{z n}$ and $\mathrm{V}_{\mathrm{Cu}}$ defects. A high density of defects in Kesterite compounds has been experimentally reported, which contribute to a degradation of device performance. ${ }^{[31]}$ In particular, as $\mathrm{Cu}$ and $\mathrm{Zn}$ radii are somewhat similar, it is very likely the formation of $\mathrm{Cu}_{\mathrm{Zn}}$ and $\mathrm{Zn}_{\mathrm{Cu}}$ defects. Consequently, there is a need to replace $\mathrm{Cu}$ and or $\mathrm{Zn}$ atoms with other of different size to avoid substitutional 


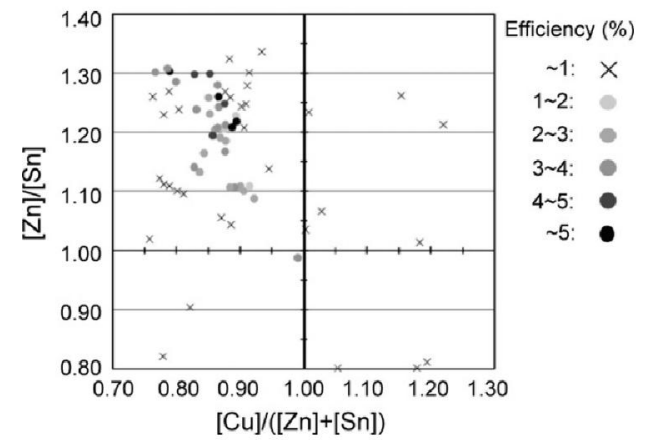

Figure 5 Kesterite solar cell efficiency as a function of $\mathrm{Cu} /$ $(\mathrm{Zn}+\mathrm{Sn})$ and $\mathrm{Zn} / \mathrm{Sn}$ compositional ratios. ${ }^{[27]}$

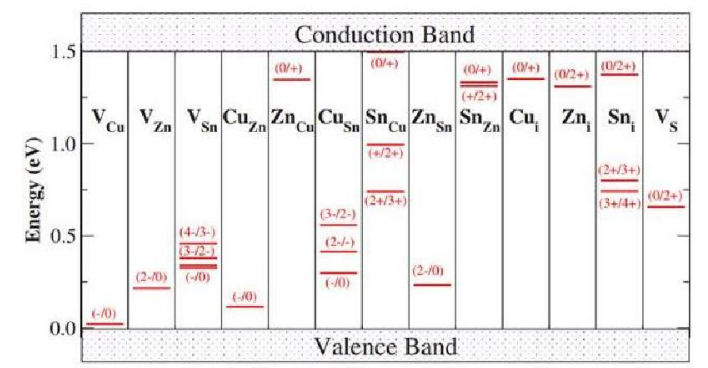

Figure 6 Defects formation for Kesterite semiconductor. ${ }^{[0]}$

defects. The impact of defects on solar cell characteristics is more clearly depicted from Internal Quantum Efficiency (IQE) and photoluminescence $(\mathrm{PL})$ measurements when comparing CIGS and CZTSSe solar cells as shown in Figure $7 .{ }^{[32]}$ The slow decay in the IQE below band-gap as well as the red shift of the PL peak respect to band-gap and the broadening of the PL peak can be associated to band tailing arising from band-gap fluctuations as a result of a high density of defects formed within Kesterite band-gap. Particularly, for Kesterite thin films deposited by spray-pyrolysis, a high density of defects of about $10^{18} \mathrm{~cm}^{-3}$ has been reported. ${ }^{[1]}$

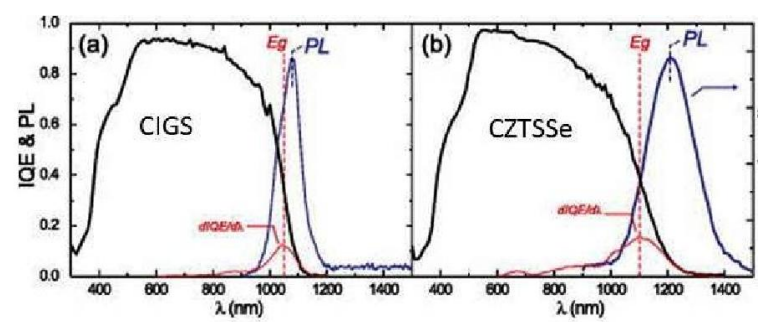

Figure 7 Comparison of IQE and PL between CIGS and CZTSSe solar cells. ${ }^{[32]}$

On the other hand, it has been previously demonstrated that defects play a fundamental role under the electric field of p-n junction contributing to enhancing carrier recombination through tunneling mechanisms. ${ }^{[20-23]}$ Under a tunneling enhanced recombination mechanism, efficiencies lower than $13 \%$ are expected as experimentally observed for Kesterite solar cells. ${ }^{[23]}$ Therefore, in order to overcome the barrier of $13 \%$ of Kesterite solar cell efficiency, further studies focused on improving Kesterite crystalline quality are required.

\section{Defects at Kesterite/buffer interface and band alignment}

Defects at Kesterite/buffer interface and band-alignment are other important aspects to be considered. Due to the fact that Kesterite compounds and CdS material, which is commonly used as n-type semiconductor, present different crystallographic structures and lattice parameters, there is a high density of defects that are formed at Kesterite/buffer interface, creasing carrier recombination and reducing in turn $V_{o c}$ values. Such defects can also favor an increase of recombinations through tunneling mechanisms as observed in Kesterite solar cells processed by spray pyrolysis. ${ }^{[16]}$ Theoretical works have demonstrated that even under a high quality CZTS absorber layer, efficiency cannot overcome the barrier of $13 \% .{ }^{[23]}$ As a result, there is a need for improving not only Kesterite crystalline quality but also to achieve a better lattice matching between Kesterite and buffer layer. For this purpose, another option could be to replace the CdS material with other that fulfill important characteristics to be used as buffer layer in solar cells such as n-type conductivity, a relatively high band-gap (higher than $2 \mathrm{eV}$ ) and with a good lattice matching with Kesterite compound. In addition to points mentioned above, an adequate band-alignment between the absorber and the buffer layers is mandatory. The ideal case for solar cell applications is the absence of conduction and valence band offsets (homojunction); however, for Kesterite solar cells, two types of band-alignments have been identified, which are spike-like and cliff-like as shown in Figure $8 .{ }^{[20-23]}$ The cliff-like band alignment presents a negative impact on solar cell behavior as band-gap at interface is reduced, making easier the recombination of carriers. Consequently, buffer layer should not present a cliff-like alignment with the absorber, which is the case of CZTS/CdS junction. ${ }^{[21]}$ As a result, CdS is not a good candidate as buffer layer for CZTS solar cells. On the other hand, a spike-like band-alignment is formed between CZTSe and CdS material. ${ }^{[22]}$ Low conduction band offset values are desirable for device fabrication as relatively high band-offset values will inhibit carrier transport reducing short-circuit current density of solar cells. For CZTSe solar cells, band-offset values have shown almost negligible impact on solar cell characteristics. ${ }^{[22]}$

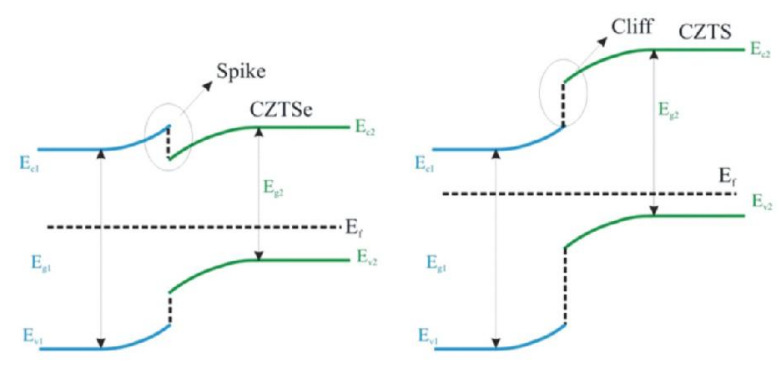

Figure 8 Band-alignment for CZTSe and CZTS solar cells.

\section{Current trends to promote Kesterite solar cell ef- ficiency}

In order to achieve higher efficiencies, several works have been published focused on improving crystalline quality of the absorber as well as replacing CdS with other buffer layers. As a first step, most authors have focused on performing different thermal annealing conditions for temperature, pressure, annealing time and the kind of atmosphere. Despite of the fact that improvements are reported, none of these works has been able to overcome the barrier of $13 \%$. An important drawback of Kesterite material is the need of a high temperature over $500^{\circ} \mathrm{C}$ for a good crystalline quality. However, it has been observed that temperatures higher than $200{ }^{\circ} \mathrm{C}$ favor the formation of Cuzn antisite defects. ${ }^{[3]}$ This could be one of the reasons why optimized thermal annealing processes have not been reached better results in solar cells. 
The partial replacement of some atoms by other elements or just the doping of Kesterite compound with other elements has been presented as an alternative way of reducing defect formation. It was firstly proposed the doping of CZTSSe with $\mathrm{Ge}$ as the partial replacement of $\mathrm{Sn}$ atoms by $\mathrm{Ge}$ will reduce defects formation due to the multivalence of Sn atoms. ${ }^{[34,35]}$ Other works have presented the doping of Kesterite compound with In and $\mathrm{Sb}^{[36,37]}$ Despite authors report improvements in comparison to reference cell, efficiency is still limited to values lower than $13 \%$. More recently, the replacement of $\mathrm{Cu}$ with $\mathrm{Ag}$ and $\mathrm{Zn}$ with $\mathrm{Cd}$ atoms has reduced the problem of band tailing. ${ }^{[38,39]}$ In particular, an $11.5 \%$ was obtained for CZTS solar cells with a partial replacement of $\mathrm{Zn}$ with $\mathrm{Cd}$ atoms about $30 \%{ }^{[40]}$ Since then, some authors have paid more attention to study the impact of Cd doping to Kesterite compound. ${ }^{[41,42]}$ However, the introduction of $\mathrm{Cd}$ is somewhat in contradiction to the idea of obtaining a low toxic material. So far, the problem of reducing Kesterite band tailing is still present, which should be solved to overcome the current limit of $13 \%$. The processing of gradedKesterite solar cells has been also proposed ${ }^{[43]}$ but efficiencies are still lower than $13 \%$.

Regarding the buffer layer, other works have proposed the replacement of CdS as buffer layer by other such as $\operatorname{In}_{2} S_{3}$, $\mathrm{ZnS}(\mathrm{O}, \mathrm{OH})$ or hybrid buffer layer ${ }^{[44-48]}$ However, despite CdS layer is not the optimal one for Kesterite solar cells, it seems to be the more appropriate among all of these. The incorporation of a nano-layer between the absorber and the buffer has been also studied to pasivate Kesterite/buffer interface ${ }^{[49]}$ but such studies are undergoing.

Finally, the strategy of a Metal-Insulator-Semiconductor (MIS) structure has been experimentally and theoretically proposed in CZTSe solar cells to increase Voc value and in turn the efficiency. ${ }^{[22,50]}$ This strategy consists of very thinning and resistive CdS layers resembling an insulator layer between the semiconductor (Kesterite) and metal (TCO). It is remarkable that efficiency up to $19 \%$ could be obtained under a very thinning and resistive CdS layers as depicted in Figure 9, which is currently quite challenging for the scientific community to obtain very resistive CdS layers. Therefore, all of these works have demonstrated that CZTSe solar cells are more adequate for solar cells as better efficiencies can be obtained only by improving Kesterite quality while CZTS solar cells requires reducing defects at both kesterite bulk and CZTS/CdS interface. In order to achieve CZTSe solar cell efficiency values higher than $13 \%$, it is mandatory either to reduce defects at bulk or achieving very resistive and thinning CdS layers, being both strategies quite challenging to scientific community.

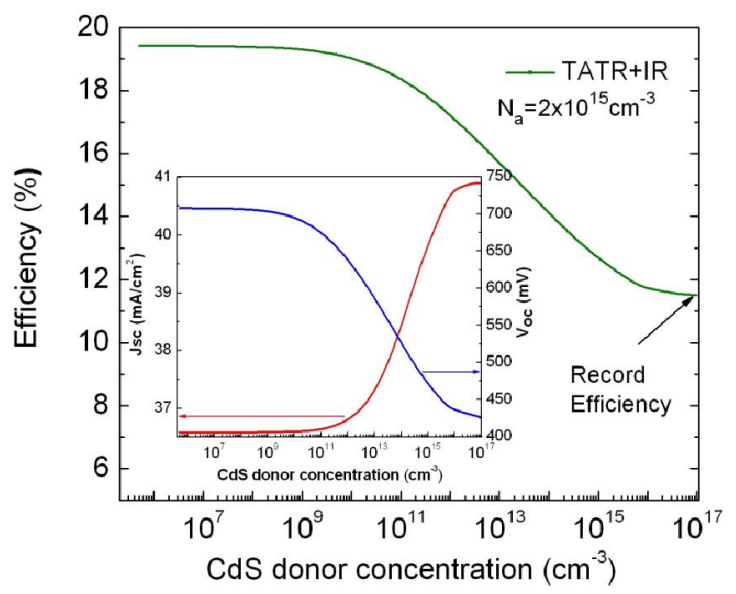

Figure 9 Efficiency, $V_{\mathrm{oc}}$ and $J_{\mathrm{sc}}$ as a function of $\mathrm{CdS}$ donor concentration for CZTSe solar cells. ${ }^{[22]}$

\section{Conclusions}

Kesterite semiconductors are quite attractive for solar cell applications since they present the adequate physical properties and consist of abundant and low toxicity elements. However, the efficiency is currently limited to a $12.6 \%$ being quite challenging to reach a new record. In this work, it was presented the main factors that are currently limiting the efficiency of Kesterite solar cells. It is demonstrated from the point of view of band alignment that CdS/CZTSe is more appropriate for solar cell applications. Bulk defects are presented as the main issue of CZTSe technology, being necessary to reduce defects formation by the partial replacement of some atoms or the use of very thinning and resistive CdS layers. Both strategies are quite challeging to the scientific community, therefore, the research on Kesterite solar cells is still undergoing.

\section{Acknowledgement}

M. Courel acknowledges the support from Universidad de Guadalajara (Programa Especial de Estímulos para Académicos de Reciente Incorporación con Perfil de Alto Nivel and PROSNI).

\section{Special Issue}

This paper is dedicated to the special issue of "Solar Cells".

\section{References}

[1] Green, M. A.; Hishikawa, Y.; Dunlop, E. D.; Levi, D. H.; Hohl-Ebinger, J.; Ho-Baillie, A. W. Y. Prog. Photovoltaics: Res. Appl. 2018, 26, 3.

[2] Vigil-Galán, O.; Courel, M.; Andrade-Arvizu, J. A.; Sánchez, Y.; Espíndola-Rodríguez, M.; Saucedo, E.; Seuret-Jiménez, D.; Titsworth, M. J. Mater. Sci.: Mater. Electron. 2015, 26, 5562.

[3] Katagiri, H.; Sasagchi, N.; Hando, S.; Hoshino, S.; Ohashi, J.; Yokota, T. Sol. Energy Mater. Sol. Cells 1997, 49, 407.

[4] Wang, W.; Winkler, M. T.; Gunawan, O.; Gokmen, T.; Todorov, T. K.; Zhu, Y.; Mitzi, D. B. Adv. Energy Mater. 2014, 4, 1301465.

[5] Wallace, S. K.; Mitzi, D. B.; Walsh, A. ACS Energy Lett. 2017, 2, 776.

[6] Fairbrother, A.; Fontané, X.; Izquierdo-Roca, V.; Espindola-Rodriguez, M.; López-Marino, S.; Placidi, M.; López-García, J.; Pérez-Rodríguez, A.; Saucedo, E. ChemPhysChem 2013, 9, 1836.

[7] Katagiri, H.; Jimbo, K.; Shwe Maw, W. I. N.; Oishi, K.; Yamazaki, M.; Araki, H.; Takeuchi, A. Thin Solid Films 2009, 517, 2455.

[8] Tanaka, T.; Kawasaki, D.; Nishio, M.; Guo, Q.; Ogawa, H. Phys. Status Solidi C 2006, 3, 2844.

[9] Moritake, N.; Fukui, Y.; Oonuki, M.; Tanaka. K.; Uchiki, H. Phys. Status Solidi C 2009, 6, 1233.

[10] Zhou, Z.; Wang, Y.; Xu, D.; Zhang, Y. Sol. Energy Mater. Sol. Cells 2010, 94, 2042.

[11] Scragg, J. J.; Dale, P. J.; Peter, L. M.; Zoppi, G.; Forbes, I. A. N. Phys. Status Solidi B 2008, 245, 1772.

[12] Moriya, K.; Watabe, J.; Tanaka, K.; Uchiki, H. Phys. Status Solidi C 2006, 3, 2848

[13] Suresh Babu, G.; Kishore Kumar, Y. B.; Uday Bhaskar, P.; Raja Vanjari, S. Sol. Energy Mater. Sol. Cells 2010, 94, 221

[14] Bag, S.; Gunawan, O.; Gokmen, T.; Zhu, Y.; Todorov, T. K.; Mitzi, D. B. Energy Environ. Sci. 2012, 5, 7060.

[15] Courel, M.; Valencia-Resendiz, E.; Pulgarín-Agudelo, F. A.; Vigil-Galán, O. Solid State Electron. 2016, 118, 1.

[16] Courel, M.; Valencia-Resendiz, E.; Andrade-Arvizu, J. A.; Saucedo, E.; Vigil-Galán, O. Sol. Energy Mater. Sol. Cells 2017, 159, 151.

[17] Courel, M.; Andrade-Arvizu, J. A.; Guillén-Cervantes, A.; Nicolás- 


\section{General Chemistry}

Marín, M. M.; Pulgarín-Agudelo, F. A.; Vigil-Galán, O. Mater. Des. 2017, 114, 515.

[18] Chen, S.; Walsh, A.; Yang, J.; Gong, X. G.; Sun, L.; Yang, P. X.; Chu, J. H.; Wei, S. H. Phys. Rev. B 2011, 83, 125201.

[19] Shockley, W.; Queisser, Hans J. J. Appl. Phys. 1961, 32, 510.

[20] Courel, M.; Andrade-Arvizu, J.A.; Vigil-Galán, O. Appl. Phys. Lett. 2014, 105, 233501.

[21] Courel, M.; Andrade-Arvizu, J.A.; Vigil-Galán, O. Solid State Electron. 2015, 111, 243.

[22] Courel, M.; Pulgarín-Agudelo, F. A.; Andrade-Arvizu, J. A.; Vigil-Galán, O. Sol. Energy Mater. Sol. Cells 2016, 149, 204

[23] Courel, M.; Andrade-Arvizu, J. A.; Vigil-Galán, O. Mater. Res. Express 2016, 3, 095501.

[24] Vigil-Galán, O.; Espíndola-Rodríguez, M.; Courel, M.; Fontané, X.; Sylla, D.; Izquierdo-Roca, V.; Fairbrother, A.; Saucedo, E.; PérezRodríguez, A. Sol. Energy Mater. Sol. Cells 2013, 117, 246.

[25] Kumar, M.; Dubey, A.; Adhikari, N.; Venkatesan, S.; Qiao, Q. Energy Environ. Sci. 2015, 8, 3134.

[26] Du, H.; Yan, F.; Young, M.; To, B.; Jiang, C. S.; Dippo, P.; Kuciauskas, D.; Chi, Z. H.; Lund, E. A.; Hancock, C.; Hlaing, O. O. W. M.; Scarpulla, M. A.; Teeter, G. J. Appl. Phys. 2014, 115, 173502.

[27] Katagiri, H.; Jimbo, K.; Tahara, M.; Araki, H.; Oishi, K. Mater. Res. Soc. Symp. Proc. 2009, 1165, M04-01.

[28] Chen, S.; Gong, X. G.; Walsh, A.; Wei, S. H. Appl. Phys. Lett. 2010, 96, 021902

[29] Xie, H.; Sanchez, Y.; López-Marino, S.; Espíndola-Rodríguez, M.; Neuschitzer, M.; Sylla, D.; Fairbrother, A.; Izquierdo-Roca, V.; Pérez-Rodríguez, A.; Saucedo, E. ACS Appl. Mater. Interfaces 2014, 6, 12744.

[30] Chen, S; Yang, J. H.; Gong, X. G.; Walsh, A.; Wei, S. H. Phys. Rev. B 2010, 81, 245204.

[31] Courel, M.; Vigil-Galan, O.; Jimenez-Olarte, D.; EspındolaRodrıguez, M.; Saucedo, E. J. Appl. Phys. 2014, 116, 134503.

[32] Gokmen, T.; Gunawan, O.; Todorov, T. K.; Mitzi, D. B. Appl. Phys. Lett. 2013, 103, 103506.

[33] Rey, G.; Weiss, T. P.; Sendler, J.; Finger, A.; Spindler, C.; Werner, F.; Melchiorre, M.; Hála, M.; Guennou, M.; Siebentritt, S. Sol. Energy Mater. Sol. Cells 2016, 151, 131.

[34] Hages, C. J.; Levcenco, S.; Miskin, C. K.; Alsmeier, J. H.; AbouRas, D.; Wilks, R. G.; Bär, M.; Unold, T.; Agrawal, R. Prog. Photovoltaics Res. Appl. 2015, 23, 376.

[35] Khadka, D. B.; Kim, S. Y.; Kim, J. H. J. Phys. Chem. C 2016, 120, 4251.
[36] Kuo, D. H.; Tseg, M. Jpn. J. Appl. Phys. 2014, 53, 035801.

[37] Tai, K. F.; Fu, D.; Chiam, S. Y.; Huan, C. H. A.; Batabyal, S. K.; Wong, L. H. ChemSusChem 2015, 8, 3504.

[38] Chagarov, E.; Sardashti, K.; Kummel, A. C.; Seog, L. Y.; Haight, R.; Gershon, T. S. J. Chem. Phys. 2016, 144, 104704.

[39] Su, Z.; Li, W.; Asim, G.; Fan, T. Y.; Wong, L. H. IEEE Photovolt. Spec. Conf. 2016, 43, 0534.

[40] Yan, C.; Sun, K.; Huang, J.; Johnston, S.; Liu, F.; Veettil, B. P.; Sun, K.; Pu, A.; Zhou, F.; Stride, J. A.; Green, M. A.; Hao, X. ACS Energy Lett. 2017, 2, 930.

[41] Zhang, Q.; Deng, H.; Chen, L.; Yu, L.; Tao, J.; Sun, L.; Yang, P.; Chu, J. J. Alloy. Compd. 2017, 695, 482.

[42] Meng, L.; Yao, B.; Li, Y.; Ding, Z.; Xiao, Z.; Liu, K.; Wang. G. J. Alloy. Compd. 2017, 710, 403.

[43] Yang, K.-J.; Son, D.-H.; Sung, S.-J.; Sim, J.-H.; Kim, Y.-IIl; Park, S.-N.; Jeon, D.-H.; Kim, J. S.; Hwang, D.-K.; Jeon, C.-W.; Nam, D.; Cheong, H.; Kang, J.-K.; Kim, D.-H. J. Mater. Chem. A 2016, 4, 10151.

[44] Jiang, F.; Ozaki, C.; Gunawan; Harada, T.; Tang, Z.; Minemoto, T.; Nose, Y.; Ikeda, S. Chem. Mater. 2016, 28, 3283

[45] Kim, J.; Hiroi, H.; Todorov, T. K.; Gunawan, O.; Kuwahara, M.; Gokmen, T.; Nair, D.; Hopstaken, M.; Shin, L., Byungha, Y. S.; Wang, W.; Sugimoto, H.; Mitzi, D. B. Adv. Mater. 2014, 26, 7427.

[46] Hiroi, Homare; Sakai, Noriyuki; Kato, Takuya; Sugimoto, Hiroki. IEEE Photovolt. Spec. Conf. 2013, 39, 863.

[47] Hiroi, H.; Kim, J.; Kuwahara, M.; Todorov, T. K.; Nair, D.; Hopstaken, M.; Zhu, Y.; Gunawan, O.; Mitzi, D. B.; Sugimoto, H. IEEE Photovolt. Spec. Conf. 2014, 40, 30.

[48] Neuschitzer, M.; Lienau, K.; Guc, M.; Barrio, L. C.; Haass, S.; Prieto, J. M.; Sanchez, Y.; Espindola-Rodriguez, M.; Romanyuk, Y.; Perez-Rodriguez, A.; Izquierdo-Roca, V.; Saucedo, E. J. Phys. D Appl. Phys. 2016, 49,125602.

[49] Erkan, M. E.; Chawla, V.; Scarpulla, M. A. J. Appl. Phys. 2016, 119, 194504.

[50] Sanchez, Y.; Neuschitzer, M.; Dimitrievska, M.; EspindolaRodriguez, M.; Lopez-Garcia, J.; IzquierdoRoca, V.; Vigil-Galán, O.; Saucedo, E. IEEE Photovolt. Spec. Conf. 2014, 40, 0417.

Received June 23, 2018 Accepted July 15, 2018 